\title{
UPDATES REGARDING AUDIT REPORTING
}

\author{
Daniel Botez \\ Vasile Alecsandri University of Bacău \\ daniel63331@yahoo.com
}

\begin{abstract}
In 2009, the International Federation of Professional Accountants - IFAC initiated a process of reviewing reporting standards. The purpose of this process is to improve the auditor's way of communicating and to increase the relevance of the audit globally, meaning that the auditor's report is more informative by presenting more information about the entity and about the audit of the financial statements. Thus, reporting standards have been amended, a new standard has been published, and the impact of these changes on other standards used by the auditor has been reported. The most relevant aspects concern the introduction of new paragraphs in the auditor's report regarding key aspects of the audit and the assumption of business continuity. Also, the structure of the report has been modified.
\end{abstract}

\section{Keywords}

International Standards on Auditing; auditing reporting; key audit matters

\section{JEL Classification}

M42

\section{Introduction}

For a long time, there have been concerns related to the way the auditor's report can increase the value of communication in the public interest of the auditor. They can be summarized in three periods.

The first period of research and consultation was completed in May 2011 when IFAC published a public consultation document on increasing the relevance of audit reporting. It was based on academic research on the subject, which ran from 2006-2009, and on the synthesis and review of national initiatives or practices between 2009 and 2010.

The second period of standard development began in December 2011 with the presentation of the project proposal and was finalized through the intervention of the working group and the project completion teams on the subject in January 2012.

The final period, the public consultation, implied the invitation to discussions in July 2012 and the publication of the project in June 2013.

Finally, in January 2015, IFAC has published the set of amended auditing standards with effective date of coming into force before or starting December 15, 2016.

The revised ISA Standards Package on reporting includes:

$\checkmark$ ISA 700 "Forming an Opinion and Reporting on Financial Statements"

$\checkmark$ ISA 701 "Communication of Audit Key Issues in the Independent Auditor's Report"

$\checkmark$ ISA 705 "Changes in Opinion in the Independent Auditor's Report"

$\checkmark$ ISA 706 "Paragraphs to highlight issues and paragraphs on other matters in the auditor's report"

$\checkmark$ ISA 720 "Auditor's Responsibilities regarding other information"

$\checkmark$ ISA 570 "Business Continuity"

$\checkmark$ ISA 260 "Communication with those responsible for governance" 


\section{Reporting news}

To summarize, the main changes foreseen in the revised form of ISA 700 "Forming an Opinion and Reporting on Financial Statements" (IAASB, 2017, pp. 718-773) are as follows:

- The auditor's opinion will be presented as the first section of the report and all sections will have a subtitle that will increase accessibility and lead to the best structure of the report;

- Improving reporting to increase transparency and clarifying responsibilities, such as an auditor's statement regarding the compliance with independence requirements and other ethical responsibilities, the name of the engagement partner (for listed entities only), expanding the description of the auditor's responsibility and key audit features, as well as the description of management and auditor's responsibilities for the continuity of business;

- A new section in the auditor's report regarding other information when such information is presented together with the audited financial statements;

- Where applicable, information on the presumption of business continuity;

- To form an opinion on the financial statements based on the evaluation of the conclusions drawn resulted from the evidence collection;

- Clearly expressing this opinion in a written report.

These requirements supplement those which remain in force and which constitute the core of this standard. The auditor should obtain reasonable assurance that the financial statements as a whole are free from significant misstatement due to fraud or error. For this he has to consider some essential aspects.

First of all, the auditor shall form his opinion only after obtaining sufficient and adequate audit evidence. For this, he has to assess the extent to which uncorrected misstatements are significant, individually or cumulatively.

It also assesses the extent to which the financial statements adequately represent the selected accounting policies and that the selected accounting policies are consistent with the applicable and appropriate financial reporting framework.

In the same sense, the auditor convinces himself that the management's estimates are reasonable, that the information presented is relevant, credible, comparable and comprehensible, and that it is presented appropriately for users to understand the effect of significant events and transactions.

Last but not least, it is determined whether the terminology used is appropriate and the extent to which the financial statements achieve a fair presentation.

When the financial statements are prepared, in significant ways, in accordance with the general financial reporting framework, the auditor expresses a unanimous opinion.

If the auditor concludes that the financial statements are materially misstated or that he cannot obtain sufficient and appropriate audit evidence,

he will change his opinion in accordance with the requirements of ISA 705 "Changes to the Opinion of the Independent Auditor's Report".

\section{Structure of the audit report according to the new requirements}

The auditor's report presents a different structure by including some additional paragraphs, completing the information provided by the existing ones and changing their location. Thus, the structure of the report is as follows:

\section{- Title}

The report must have a title that clearly shows that it is the report of an independent auditor. We suggest using the "Statutory Auditor's Report" title.

\section{- The recipient}


The requirements stipulate that the report should be addressed according to the circumstances of the engagement, but it may be that the law, regulations or terms of the engagement may provide for the addressee of the auditor's report under the specific legal conditions.

Typically, the report is addressed to those for whom it is drawn up, i.e. to shareholders or to those responsible for governance.

\section{- Opinion}

This section includes the auditor's opinion and some elements considered absolutely necessary:

$\checkmark$ the identification of the entity whose financial statements have been audited

$\checkmark$ the statement that the financial statements have been audited

$\checkmark$ identifying the title of each component

$\checkmark$ a reference to notes, including a summary of significant accounting policies

$\checkmark$ the specification of the date or period covered by each of the components of the financial statements

$\checkmark$ the use of the expressions "present fairly in all significant aspects" or "present a true and fair view".

\section{- Basics of opinion (bases for opinion)}

In this paragraph, the auditor presents some of the elements underlying his opinion. Firstly, he makes a statement that the audit was conducted in accordance with ISAs standards and makes a reference to the section of the report describing the auditor's responsibility for complying with ISAs.

Also, this paragraph contains a statement by the auditor that he is independent of the entity in accordance with relevant ethical requirements for auditing, compliance by the auditor with any other ethical responsibilities, indicating jurisdiction over ethical requirements, or reference to the Code of Ethics.

Also in this paragraph, the auditor declares that the evidence obtained is sufficient and appropriate to support the opinion.

- Going concern, in accordance with the provisions of ISA 570 "Going concern" (IAASB, 2017, pp. 575-604)

When the auditor considers that the going concern assumption is inappropriate as the basis for the preparation of the financial statements, he will provide a contrary view.

If the auditor considers the appropriate continuity assumption but there are significant uncertainties, he proceeds differently depending on the circumstances.

If there is adequate disclosure in the financial statements, the auditor provides an unchanged opinion but includes a separate section under the heading "Significant business continuity uncertainties" in the report, in which he draws attention to the notes in the financial statements in which these matters are presented and states these issues. There is also the possibility of doubting the continuity of the entity's activity in the future and that its opinion is not changed from this point of view.

If significant uncertainties are not adequately disclosed in the financial statements, the auditor expresses a supportive opinion or an opinion, and in the paragraph on the bases of opinion he states that the uncertainties exist and that they are not adequately disclosed in the financial statements.

If management has not evaluated or extended the continuity assessment, including the auditor's request, the implications for the report should be studied.

\section{- Key audit matters}

The presentation of the key aspects that the auditor identified during the audit is mandatory for audited entities when the auditor is bound by law or regulation, or when the information regarding this aspect is required in compliance with ISA 701 Standard "Communication Key audit matters in the independent auditor's report." (IAASB, 2017, pp. 774-797) 
The purpose of communicating key audit aspects is to increase the auditor's report communication value through the transparency of the audit.

The communication of key aspects provides users with additional information on those issues considered significant by the auditor.

The auditor's objectives are to determine the key audit aspects and, once he has formed an opinion on the financial statements, to communicate these issues by describing them in the auditor's report.

Communicating these issues is not a substitute for:

$\checkmark$ The presentation of the applicable financial reporting framework used by management for accurate presentation;

$\checkmark$ The auditor' s ability to express a modified opinion when he considers it necessary;

$\checkmark$ To report significant uncertainty about business continuity;

$\checkmark$ It is not a separate opinion on a particular aspect.

The auditor determines or identifies key issues with respect to the areas assessed as being of high risk of material misstatement or significant risks, significant professional judgment on the elements which supposed the management's judgment, including the accounting estimates for which uncertainties were identified or the effect of the audit on events and on significant transactions of the period.

In this paragraph, the auditor presents key issues that are significant according to the auditor's reasoning, and points out that these issues are presented in relation to the financial statements as a whole and during the process of forming an opinion, and he doesn't provide a separate opinion regarding them.

Examples of the fields from which the auditor may determine key issues are: Goodwill; The evaluation of the financial instruments; the effects of the new IFRS Standards; the assessment of assets and liabilities for the calculation of the pension fund; the recognition of revenue; the assessment of the business continuity hypothesis (IAASB, 2015b).

\section{- Responsibility of management (identification)}

Management is responsible for the preparation of the financial statements in accordance with the applicable financial reporting framework, the implementation of the internal control necessary for the preparation of the free financial statements of misstatements due to fraud or error.

Management also assesses the entity's ability to continue its business and whether the use of operating continuity as the basis for preparing the financial statements is appropriate.

\section{- Auditor's Responsibility}

The new requirements provide for a wider presentation of the auditor's responsibilities. First, as before, it sets out the audit objectives. It also states that reasonable assurance is a high level of assurance but does not guarantee that an audit performed in accordance with ISAs always detects significant distortions, if any.

It states that distortions may be due to fraud and error and describes that what is considered significant, individual or cumulative is reasonably expected to influence the decisions of the users based on the financial statements or to define or describe what is significant in accordance with the financial reporting framework.

It also states that the auditor uses professional judgment and maintains skepticism during the audit and describes an audit specifying the auditor's responsibilities:

$\checkmark$ Identify and assess the risk of material misstatement of financial statements as a result of fraud or error; Plan and perform the audit in response to these risks; To obtain sufficient and adequate evidence to support the opinion. The risk of not detecting significant misstatements due to fraud is higher than that resulting from errors, as fraud may involve forgery, intentional omissions, lack of presentation or cancellation of internal control; 
$\checkmark$ To gain an understanding of the relevant internal control in order to properly plan the procedures but not to express an opinion on its effectiveness;

$\checkmark$ Evaluate the adequacy of the accounting policies used, the reasonableness of the estimates and the transparency of the presentations;

$\checkmark$ Conclude on the suitability of management's use of the presumption of continuity of business and whether it has found evidence to cast doubt on this assumption. If there are uncertainties, they should be presented in the report and if the items are not adequately presented in the notes take into account the change of opinion;

$\checkmark$ Evaluate the overall presentation, structure and content of financial statements, including presentations, and find that events and transactions are presented in such a way as to ensure a true and fair view;

$\checkmark$ Specify that the auditor communicates to those entrusted with governance, among other things, the scope, audit period and significant findings, including those concerning internal control deficiencies.

In the particular audit situation of rated entities, the auditor specifies that he provides the entity's management with a statement of compliance with relevant ethical independence requirements, threats, and measures, and communicates to management all significant aspects of the audit and key audit issues.

The description of the auditor's responsibility for the financial statements may be included in the audit report as an attachment to the auditor's report or by reference to the website of a competent authority.

\section{- Other reporting responsibilities}

This paragraph is introduced when the auditor has other reporting responsibilities additional to those required by the International Standards on Auditing.

- Name of the mission officer (listed entities)

Given the importance of listed entities, the presentation of the name of the mission officer is an additional element of transparency. Specific legal acts may provide, in certain jurisdictions, for the submission of additional information.

- Signature of the auditor

Generally, the signature of the auditor is the signature of the person authorized to represent the audit firm.

\section{- Auditor's address}

\section{- Report date}

The date of the report delimits the auditor's responsibility for events and transactions occurring before and after that date. The auditor's behavior is set out in ISA 560 "Subsequent Events".

\section{Conclusion}

Starting with the audit report for the financial year 2016, the auditors apply the revised reporting standards. This is a challenge for both auditors and users of the report. By providing a report with more information, in an extended form, it increases its informative value, providing a better understanding of the auditor's position and its importance in the business environment.

\section{References}

IAASB (2017), Handbook of International Quality Control, Auditing, Review, Other Assurance, and Related Services Pronouncements, 2016-2017 Edition, Volume I, available at https://www.ifac.org/system/files/publications/files/2016-2017IAASB-Handbook-Volume-1.pdf 
IAASB (2015a), The New Auditor's Report: Greater Transparency into the Financial Statement Audit, available at https://www.ifac.org/system/files/publications/files/Reporting-on-AFS-New\%26-Revised-Stds-Combined 1.pdf

IAASB (2015b), Auditor Reporting - Key Audit Matters, available at https://www.ifac.org/system/files/publications/files/Auditor-ReportingToolkit-KAM-Overview.pdf

IAASB (2015c), Auditor Reporting on Going Concern, available at https://www.ifac.org/system/files/publications/files/Auditor-ReportingToolkit-Going-Concern.pdf

IAASB (2016), The New Auditor's Report: Questions and Answers, available at https://www.ifac.org/system/files/publications/files/The-New-Auditors-

Report-Questions-and-Answers_0.pdf 